Short clinical report

\title{
HUWE1 mutation explains phenotypic severity in a case of familial idiopathic intellectual disability
}

\author{
Mala Isrie ${ }^{\mathrm{a}}$, Vera M. Kalscheuer ${ }^{\mathrm{b}}$, Maureen Holvoet ${ }^{\mathrm{a}}$, Nathalie Fieremans ${ }^{\mathrm{c}}$, \\ Hilde Van Esch ${ }^{\mathrm{a}}$, Koenraad Devriendt ${ }^{\mathrm{a}, *}$ \\ ${ }^{a}$ Center for Human Genetics, University Hospitals Leuven, KU Leuven, Herestraat 49, 3000 Leuven, Belgium \\ ${ }^{\mathrm{b}}$ Max Planck Institute for Molecular Genetics, Ihnestraße 63-73, 14195 Berlin, Germany \\ ${ }^{c}$ Human Genome Laboratory, VIB, Center for Human Genetics, KU Leuven, Herestraat 49, 3000 Leuven, Belgium
}

\section{A R T I C L E I N F O}

\section{Article history:}

Received 2 March 2013

Accepted 8 May 2013

Available online 27 May 2013

\section{Keywords:}

HUWE1

Missense mutation

Intellectual disability

Chromosome X exome sequencing

\begin{abstract}
A B S T R A C T
The advent of next-generation sequencing has proven to be a key force in the identification of new genes associated with intellectual disability. In this study, high-throughput sequencing of the coding regions of the X-chromosome led to the identification of a missense variant in the HUWE1 gene. The same variant has been reported before by Froyen et al. (2008). We compare the phenotypes and demonstrate that, in the present family, the HUWE1 mutation segregates with the more severe ID phenotypes of two out of three brothers. The third brother has a milder form of ID and does not carry the mutation.
\end{abstract}

(c) 2013 Elsevier Masson SAS. All rights reserved.

\section{Introduction}

In 1991, the FMR1 gene was discovered to be responsible for the Fragile X syndrome, the most common form of X-linked intellectual disability (XLID) [1,2]. Ever since, many other genes have been reported as XLID genes [3-5]. A substantial number of such genes have been found or confirmed by presence of copy number changes on arrays targeting specifically the X-chromosome [6-9].

The advent of next-generation sequencing has proven to be another key force in the identification of new ID genes. Whereas the whole-exome sequencing approach seems to be most effective in isolated cases of ID, chromosome X exome sequencing is an alternative strategy that can be used in families with suspicion of XLID [10-12]. In this study, high-throughput sequencing of the coding regions of the $\mathrm{X}$-chromosome led us to the identification of a missense variant in the HUWE1 gene.

Copy number variants as well as missense mutations of HUWE1 have previously been reported in individuals with XLID [13]. This study deals with a comparison of the clinical features and further reinforcement of HUWE1 as an XLID gene. Moreover, we argue that careful assessment of phenotypic heterogeneity - even within a

\footnotetext{
* Corresponding author. Center for Human Genetics, University Hospitals Leuven, Katholieke Universiteit Leuven, Herestraat 49, Bus 602, 3000 Leuven, Belgium.

E-mail address: Koenraad.Devriendt@uzleuven.be (K. Devriendt).
}

family - is an important step toward correct genotype-phenotype correlations.

\section{Methods}

The study was reviewed and approved by the ethical committee of the hospital, and informed consent was obtained from the participants and/or their caretakers. All affected patients underwent clinical examination. Genomic DNA was isolated from peripheral blood according to standard procedure guidelines. FMR1 analysis and array-CGH results were normal (1 Mb BAC-array in II:1 and II:2 and 180k Oxford Gene Technology Cytosure oligoarray in II:3; see Fig. 1). Because the pedigree was consistent with an X-linked inheritance pattern, it was selected for X-exome sequencing.

For the index patient we used $3 \mu \mathrm{g}$ genomic DNA for constructing a single-end Illumina sequencing library with the Illumina Genomic DNA Single End Sample Prep kit, according to the instructions of the manufacturer. X-chromosome exome enrichment was performed for the sequencing library using the Agilent SureSelect Human X Chromosome Kit, which contains 47,657 RNA baits for 7591 exons of the human X chromosome. Single-end deep sequencing was performed on the Illumina Genome Analyzer GAIIx. Read-length was 101 nucleotides. Sequences were analyzed with in-house-developed tools.

Sanger sequencing was performed for validation of the promising variants and subsequent segregation analyses. Primers were designed 
I

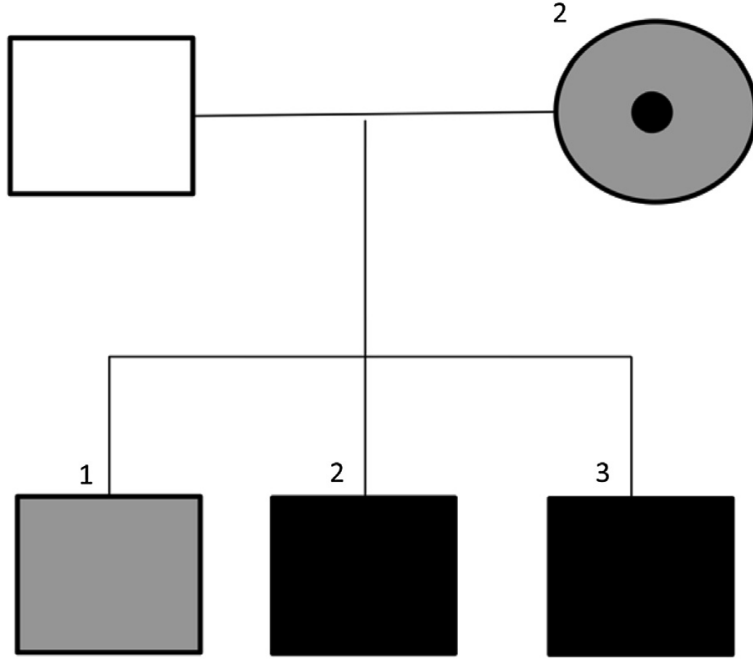

Fig. 1. Pedigree of the family.

with Primer3Plus software and GoTaq ${ }^{\circledR}$ DNA Polymerase (Promega) was used for amplification of the region of interest [14]. PCR products were sequenced on an $\mathrm{ABI} 3130 \mathrm{xl}$ sequencer (Life Technologies). [6].

$\mathrm{X}$-inactivation studies were performed as described previously

\section{Results}

\subsection{Clinical synopsis}

The three male siblings in this family all presented with intellectual disability (Fig. 1). However, the phenotype in the eldest brother (II:1) was less marked in comparison to the younger siblings (II:2 and II:3). Parents were non-consanguineous. The father had a lower educational background. The mother was normal, but clearly much more cognitively limited than her parents, brother and sister. She had hypertelorism and macrocephaly.

II: 1 was 9 years and 7 months old at the time of investigation. He had relative macrocephaly (OFC: $53.5 \mathrm{~cm}$ (p90); height $133 \mathrm{~cm}$ (p25) and weight $39 \mathrm{~kg}(\mathrm{p} 75-90)$ ) and hypertelorism. His IQ was 73. His younger brother II:2 had a more marked developmental delay. He started walking at the age of 34 months. At 4 years and 11 months his parameters were: height $105 \mathrm{~cm}$ (p10), weight $20.1 \mathrm{~kg}$ (p75) and OFC $53.4 \mathrm{~cm}$ (p90-97). He had hypertelorism, downslanting palpebral fissures, deep-set eyes and tapering fingers (see Fig. 2). There was rest edema on both hands and feet. MRI of the brain was normal. He had severe ID (IQ < 30). The youngest brother II:3 also had severe ID (IQ $<30$ ). He had a round face with downslanting palpebral fissures. He had rest edema on both hands and feet, a simian crease as well as tapering fingers. He had very small nails on his feet. At 3 years and 5 months of age his parameters were: height $97 \mathrm{~cm}$ (p50), weight $16.4 \mathrm{~kg}$ (p75) and OFC $51.5 \mathrm{~cm}$ (p75).

\subsection{Chromosome $X$ exome sequencing}

Massively parallel sequencing of all X-chromosome specific exons of the index patient II:2 (see Fig. 1) followed by filtering of the variants against frequent variants in publicly available databases, including the 1000 Genomes project database and dbSNP135 revealed five missense mutations: chrX:53581342-53581342 G $>A$ in HUWE1, chrX:90577555-90577555 T > C in PABPC5, chrX:100799179$100799179 \mathrm{C}>\mathrm{A}$ in ARMCX2, chrX:103181324-103181324 G $>\mathrm{A}$ in H2BFM and chrX:153196840-153196840 C $>\mathrm{T}$ in TKTL1 (all based on UCSC genome browser build March 2006, hg18).

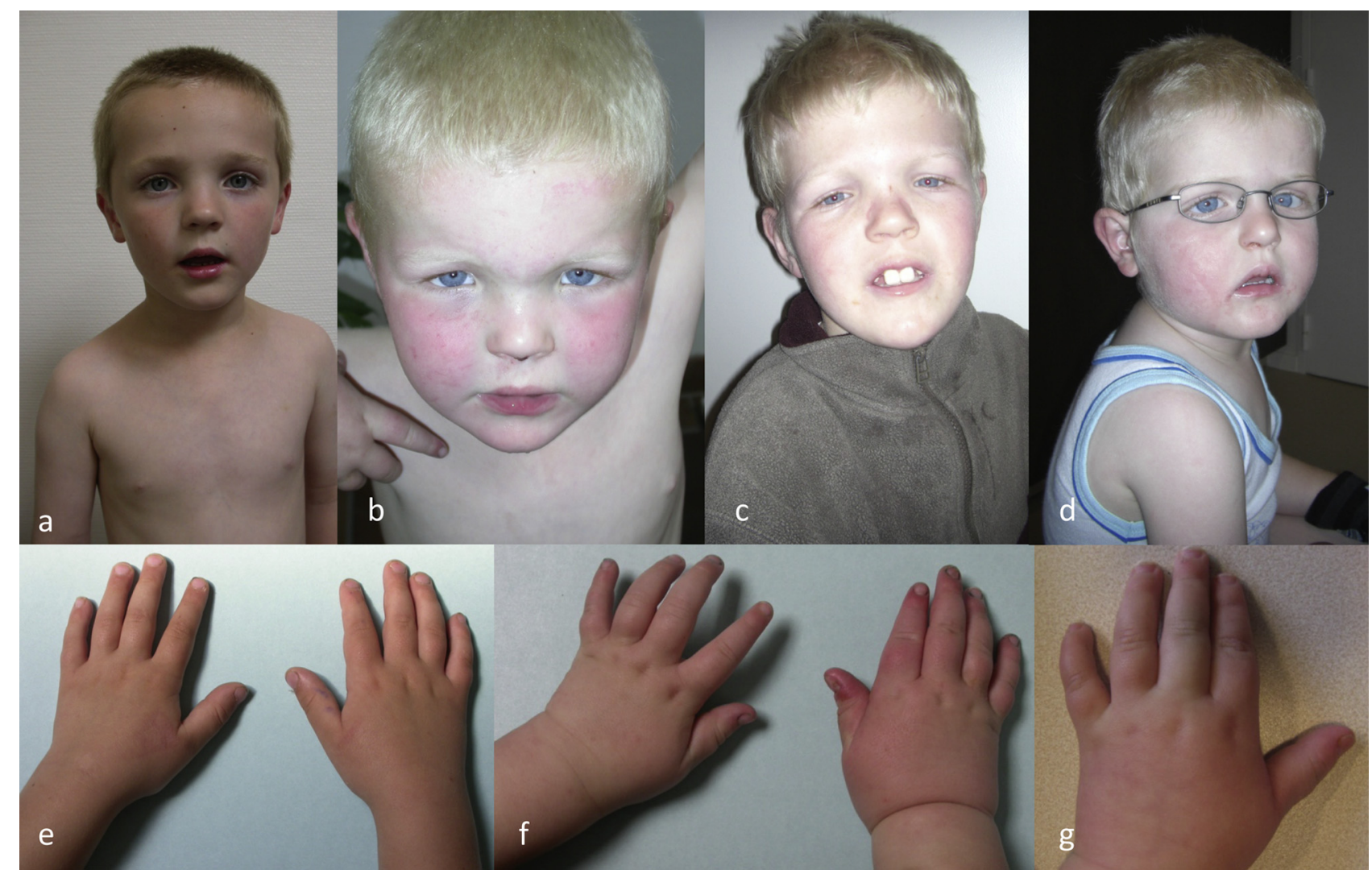

Fig. 2. Upper panel: frontal view of (a) II:1 at age 7 years (b) II:2 at age 4 and (c) 8 years (d) II:3 at age 3 years. Lower panel: hands of (e) II:1 (f) II:2 and (g) II:3. 
Mutations in HUWE1 (OMIM \#300697) and PABPC5 (OMIM \#300407) were confirmed with Sanger sequencing. Segregation analysis showed a similar pattern for both the HUWE1 (p.R4013W) as well as the PABPC5 (p.I108T) substitutions, namely that the brothers II:2 and II:3 carried both mutations, while II:1 did not. Mother was also carrier of both mutations and her X-inactivation status was random (61/39). A healthy sister of the mother did not carry the mutation and other family members were not available.

In contrast to PABPC5, HUWE1 is an established XLID gene and the same missense mutation has been reported before by Froyen et al. [13]. Therefore, we classified the HUWE1 mutation as the pathological mutation in this family. Considering limited information on and low expression levels of PABPC5 in brain and other tissues, pathogenicity of this variant is less likely, though a modifying effect on the phenotype cannot be ruled out.

\section{Discussion}

In this study we describe the presence of a HUWE1 missense mutation discovered by chromosome $\mathrm{X}$ exome sequencing in a family with idiopathic intellectual disability. Segregation analysis based on the sheer presence or absence of ID could have provided a pitfall in diagnosis, since there was an intrafamilial difference in severity of the phenotype. We demonstrate that the HUWE1 mutation segregates with the severe phenotype in some individuals from this family and therefore provides an explanation for this diversity.

Patients with a duplication involving HUWE1 are usually described to have a nonsyndromic mild to moderate ID [13,15]. Few affected individuals are reported to have minor dysmorphic features, but a consistent pattern among all duplication carriers is lacking. So far, three HUWE1 missense mutations have been reported [13]. All cases presented with nonsyndromic moderate to profound ID. Macrocephaly was present in one of the families in affected individuals as well as carrier females. Carrier females of this family also had learning difficulties [16]. Recently, a fourth HUWE1 missense mutation has been reported in a screening of patients with autism spectrum disorders [12]. This rare p.Val950Asp variant occurred de novo and is expected to be involved in the phenotype.

HUWE1 encodes an E3 ubiquitin ligase, which is involved in cancer as well as neuronal development. D'Arca et al. and Zhao et al. demonstrated an essential role of HUWE1 in development of the cerebellum and neurogenesis by studying targeted Huwe1 inactivation in the mouse brain $[17,18]$.

The p.R4013W mutation found in this family has been described previously in an Australian family [13,16]. Interestingly, macrocephaly was found in all affected members of this family, in contrast to the unaffected family members. Although relative macrocephaly is also present in our study in brothers II:1 and II:2, II:1 did not carry the mutation. Patient II:3 did carry the mutation, but had no macrocephaly. This argues that macrocephaly, although present in the majority of affected patients, is not a consistent feature. It has also not been found in two other families with different HUWE1 mutations [13]. The features that the two affected male mutation carriers in this family have in common - in contrast to their noncarrier brother - are: more severe ID, downslanting palpebral fissures, tapering fingers and rest edema on both hands and feet. The presence of tapering fingers has also been described in one of the affected individuals by Turner et al. (Patient III:14) [16].

It remains difficult to estimate the influence of the HUWE1 mutation in the mother. Her random X-inactivation status might support certain effect of the mutation on her cognitive function. The cognitive limitations of brother II:1 can most likely be explained by a multifactorial model, including genes with modifier effects: de novo or inherited from one or both parents. Exome sequencing of this patient along with the parents could help further explore this hypothesis, although the yield of such a study is questionable.

HUWE1 is a dosage-sensitive gene and copy number variations of this gene have recurrently been linked to ID [13,15]. Here, we would like to emphasize the importance of pathological point mutations in the gene. The absence of truncating mutations of HUWE1 might be explained by prenatal male lethality, similar to the absence of HUWE1 deletion reports. The combination of XLID, downslanting palpebral fissures and tapering fingers with or without macrocephaly might be recurrent features of the HUWE1 ID phenotype, though this will need to be confirmed by additional patient reports.

\section{References}

[1] A.J. Verkerk, M. Pieretti, J.S. Sutcliffe, Y.H. Fu, D.P. Kuhl, A. Pizzuti, O. Reiner, S. Richards, M.F. Victoria, F.P. Zhang, Identification of a gene (FMR-1) containing a CGG repeat coincident with a breakpoint cluster region exhibiting length variation in fragile X syndrome, Cell 65 (1991) 905-914.

[2] E.J. Kremer, M. Pritchard, M. Lynch, S. Yu, K. Holman, E. Baker, S.T. Warren, D. Schlessinger, G.R. Sutherland, R.I. Richards, Mapping of DNA instability at the fragile $X$ to a trinucleotide repeat sequence $\mathrm{p}(\mathrm{CCG}) \mathrm{n}$, Science 252 (1991) 1711-1714.

[3] A.P. de Brouwer, H.G. Yntema, T. Kleefstra, D. Lugtenberg, A.R. Oudakker, B.B. de Vries, H. van Bokhoven, H. Van Esch, S.G. Frints, G. Froyen, J.P. Fryns, M. Raynaud, M.P. Moizard, N. Ronce, A. Bensalem, C. Moraine, K. Poirier, L. Castelnau, Y. Saillour, T. Bienvenu, C. Beldjord, V. des Portes, J. Chelly, G. Turner, T. Fullston, J. Gecz, A.W. Kuss, A. Tzschach, L.R. Jensen, S. Lenzner, V.M. Kalscheuer, H.H. Ropers, B.C. Hamel, Mutation frequencies of X-linked mental retardation genes in families from the EuroMRX consortium, Hum. Mutat. 28 (2007) 207-208.

[4] P. Chiurazzi, C.E. Schwartz, J. Gecz, G. Neri, XLMR genes: update 2007, Eur. J. Hum. Genet. 16 (2008) 422-434.

[5] J. Gécz, C. Shoubridge, M. Corbett, The genetic landscape of intellectual disability arising from chromosome X, Trends Genet. 25 (2009) 308-316.

[6] G. Froyen, H. Van Esch, M. Bauters, K. Hollanders, S.G. Frints, J.R. Vermeesch, K. Devriendt, J.P. Fryns, P. Marynen, Detection of genomic copy number changes in patients with idiopathic mental retardation by high-resolution Xarray-CGH: important role for increased gene dosage of XLMR genes, Hum. Mutat. 28 (2007) 1034-1042.

[7] M. Bauters, H. Van Esch, P. Marynen, G. Froyen, X chromosome array-CGH for the identification of novel X-linked mental retardation genes, Eur. J. Med. Genet. 48 (2005) 263-275.

[8] I. Madrigal, L. Rodríguez-Revenga, L. Armengol, E. González, B. Rodriguez, C. Badenas, A. Sánchez, F. Martínez, M. Guitart, I. Fernández, J.A. Arranz, M. Tejada, L.A. Pérez-Jurado, X. Estivill, M. Milà, X-chromosome tiling path array detection of copy number variants in patients with chromosome Xlinked mental retardation, BMC Genomics 8 (2007) 443.

[9] A.C. Whibley, V. Plagnol, P.S. Tarpey, F. Abidi, T. Fullston, M.K. Choma, C.A. Boucher, L. Shepherd, L. Willatt, G. Parkin, R. Smith, P.A. Futreal, M. Shaw, J. Boyle, A. Licata, C. Skinner, R.E. Stevenson, G. Turner, M. Field, A. Hackett, C.E. Schwartz, J. Gecz, M.R. Stratton, F.L. Raymond, Fine-scale survey of X chromosome copy number variants and indels underlying intellectual disability, Am. J. Hum. Genet. 87 (2010) 173-188.

[10] P.S. Tarpey, R. Smith, E. Pleasance, A. Whibley, S. Edkins, C. Hardy, S. O'Meara, C. Latimer, E. Dicks, A. Menzies, P. Stephens, M. Blow, C. Greenman, Y. Xue, C. Tyler-Smith, D. Thompson, K. Gray, J. Andrews, S. Barthorpe, G. Buck, J. Cole, R. Dunmore, D. Jones, M. Maddison, T. Mironenko, R. Turner, K. Turrell, J. Varian, S. West, S. Widaa, P. Wray, J. Teague, A. Butler, A. Jenkinson, M. Jia, D. Richardson, R. Shepherd, R. Wooster, M.I. Tejada, F. Martinez, G. Carvill, R. Goliath, A.P. de Brouwer, H. van Bokhoven, H. Van Esch, J. Chelly, M. Raynaud, H.H. Ropers, F.E. Abidi, A.K. Srivastava, J. Cox, Y. Luo, U. Mallya, J. Moon, J. Parnau, S. Mohammed, J.L. Tolmie, C. Shoubridge, M. Corbett, A. Gardner, E. Haan, S. Rujirabanjerd, M. Shaw, L. Vandeleur, T. Fullston, D.F. Easton, J. Boyle, M. Partington, A. Hackett, M. Field, C. Skinner, R.E. Stevenson, M. Bobrow, G. Turner, C.E. Schwartz, J. Gecz, F.L. Raymond, P.A. Futreal, M.R. Stratton, A systematic, large-scale resequencing screen of X-chromosome coding exons in mental retardation, Nat. Genet. 41 (2009) 535-543.

[11] J.J. Johnston, J.K. Teer, P.F. Cherukuri, N.F. Hansen, S.K. Loftus, K. Chong, J.C. Mullikin, L.G. Biesecker, N.I.S.C. (NISC), Massively parallel sequencing of exons on the X chromosome identifies RBM10 as the gene that causes a syndromic form of cleft palate, Am. J. Hum. Genet. 86 (2010) 743-748.

[12] C. Nava, F. Lamari, D. Héron, C. Mignot, A. Rastetter, B. Keren, D. Cohen, A. Faudet, D. Bouteiller, M. Gilleron, A. Jacquette, S. Whalen, A. Afenjar, D. Périsse, C. Laurent, C. Dupuits, C. Gautier, M. Gérard, G. Huguet, S. Caillet, B. Leheup, M. Leboyer, C. Gillberg, R. Delorme, T. Bourgeron, A. Brice, C. Depienne, Analysis of the chromosome X exome in patients with autism 
spectrum disorders identified novel candidate genes, including TMLHE, Transl. Psychiatry 2 (2012) e179.

[13] G. Froyen, M. Corbett, J. Vandewalle, I. Jarvela, O. Lawrence, C. Meldrum, M. Bauters, K. Govaerts, L. Vandeleur, H. Van Esch, J. Chelly, D. Sanlaville, H. van Bokhoven, H.H. Ropers, F. Laumonnier, E. Ranieri, C.E. Schwartz, F. Abidi, P.S. Tarpey, P.A. Futreal, A. Whibley, F.L. Raymond, M.R. Stratton, J.P. Fryns, R. Scott, M. Peippo, M. Sipponen, M. Partington, D. Mowat, M. Field, A. Hackett, P. Marynen, G. Turner, J. Gécz, Submicroscopic duplications of the hydroxysteroid dehydrogenase HSD17B10 and the E3 ubiquitin ligase HUWE1 are associated with mental retardation, Am. J. Hum. Genet. 82 (2008) 432-443.

[14] S. Rozen, H. Skaletsky, Primer3 on the WWW for general users and for biologist programmers, Methods Mol. Biol. 132 (2000) 365-386.

[15] G. Froyen, S. Belet, F. Martinez, C.B. Santos-Rebouças, M. Declercq, J. Verbeeck, L. Donckers, S. Berland, S. Mayo, M. Rosello, M.M. Pimentel, N. FintelmanRodrigues, R. Hovland, S. Rodrigues dos Santos, F.L. Raymond, T. Bose, M.A. Corbett, L. Sheffield, C.M. van Ravenswaaij-Arts, T. Dijkhuizen, C. Coutton, V. Satre, V. Siu, P. Marynen, Copy-number gains of HUWE1 due to replication- and recombination-based rearrangements, Am. J. Hum. Genet. 91 (2012) 252-264.
[16] G. Turner, A. Gedeon, J. Mulley, X-linked mental retardation with heterozygous expression and macrocephaly: pericentromeric gene localization, Am. J. Med. Genet. 51 (1994) 575-580.

[17] D. D'Arca, X. Zhao, W. Xu, N.C. Ramirez-Martinez, A. Iavarone, A. Lasorella Huwe1 ubiquitin ligase is essential to synchronize neuronal and glial differentiation in the developing cerebellum, Proc. Natl. Acad. Sci. U. S. A. 107 (2010) 5875-5880.

[18] X. Zhao, D. D’Arca, W.K. Lim, M. Brahmachary, M.S. Carro, T. Ludwig C.C. Cardo, F. Guillemot, K. Aldape, A. Califano, A. Iavarone, A. Lasorella, The NMyc-DLL3 cascade is suppressed by the ubiquitin ligase Huwe1 to inhibit proliferation and promote neurogenesis in the developing brain, Dev. Cell 17 (2009) 210-221.

\section{Web resources}

[19] Database of Single Nucleotide Polymorphisms (dbSNP). Bethesda (MD): National Center for Biotechnology Information, National Library of Medicine: http://www.ncbi.nlm.nih.gov/SNP/.

[20] 1000 Genomes Project Browser: http://browser.1000genomes.org/index.html. 